\title{
Life, Architecture, Mathematics, and the Fourth Dimension
}

\author{
Snezana Lawrence
}

Published online: 8 January 2015

(C) Kim Williams Books, Turin 2014

\begin{abstract}
The fourth dimension, whilst contemplated from as far back as antiquity, was only studied in mathematics from the nineteenth century. Here we trace the history of these investigations, and place them in the context of their manifestations in architecture, whether real or imagined. As we take a look at the social milieu within which the study of the fourth dimension flourished, in the nineteenth and early twentieth centuries, we investigate the biographies and works of the protagonists, and note that the study of the fourth dimension, and dimensionality itself, was strongly coloured by considerations of ethics and even religiosity. Finally we look at a few examples of architecture which offer different interpretations of the fourth dimension.
\end{abstract}

Keywords Polytopes Polyhedra · Fourth dimension · Dimensionality ·

Schläfli symbol · Tesseract · Euler's characteristics · Spiritualism ·

Theosophy · Antroposophy · Flatland

\section{Introduction}

When searching for links between mathematics and architecture that are difficult to describe, we stumble upon the higher dimensions: we have few options for understanding this concept, and even fewer possibilities of materializing it in an architectural creation. Perhaps this feeling of being 'stuck' in our three-dimensional world is somehow alleviated by the invention of the parallel e-universe and the possible architectures of our increasingly networked digital world and the internet. Nineteenth-century researchers grappled with dimensionality in a different way, as will shortly become apparent.

S. Lawrence (西)

School of Education, Bath Spa University, Newton St Loe, Bath BA2 9BN, UK

e-mail: snezana@mathsisgoodforyou.com 
The first dimension higher than the one we are used to experiencing and take for granted is of course the fourth. As a concept the fourth dimension can trace its roots back to classical times, but was developed in the nineteenth century by mathematicians, some of whom were either amateur mathematicians or stumbled upon it in their research related to a number of other sciences. Aristotle discussed dimensionality in De Caelo, ${ }^{1}$ and Ptolemy denied and disproved the existence of the dimensions higher than the third, but nevertheless contemplated it. ${ }^{2}$ Many centuries later, the English mathematician John Wallis began to interrogate the possibility of the extension of three into further dimensions although he dismissed it at the outset:

A line drawn into a line shall make a plane or surface; this drawn into a line, shall make a solid: But if this solid be drawn into a line, or this plane into a plane, what shall it make? A plano-plane? That is a monster in nature, and less possible than a Chimaera or Centaure. For length, breadth and thickness, take up the whole of space. Nor can our Fansie imagine how there should be a fourth local dimension beyond these three (Wallis 1685: 126).

During the French Revolution, the revolutionary mathematicians D'Alembert and Lagrange $^{3}$ were the first to accept the possibility that the fourth dimension can be considered to be time. Lagrange in particular spoke of three coordinates to describe the space of three dimensions, and introduced the fourth as the function of time (Lagrange 1797: 223). He then justified the introduction of the fourth dimension by denoting it $t$ and showing that it has already been considered in mechanics, hence making it acceptable to adopt such practice elsewhere.

Therefore, whilst people have grappled with the concept for a very long time and occasionally considered it in greater depth, only to regularly refuse to deal with it, finally in the nineteenth century the doors were re-opened to this area of geometrical investigations. Perhaps it was the invention of non-Euclidean geometries, or the projective geometry, or even the social upheavals of the preceding (revolutionary) era, or a mixture of all of these, but in any case the possibility of describing the fourth dimension mathematically, even if it is difficult to imagine it physically, began to resurface.

\footnotetext{
1 'A magnitude if divisible one way is a line, if two ways a surface, and if three a body. Beyond these there is no other magnitude, because the three dimensions are all that there are, and that which is divisible in three directions is divisible in all' (Aristotle 2012, 268a:10-15). But the possibility of an extension of dimensions appeared to Aristotle, although he rejected it little later: 'All magnitudes, then, which are divisible are also continuous. Whether we can also say that whatever is continuous is divisible does not yet, on our present grounds, appear. One thing, however, is clear. We cannot pass beyond body to a further kind, as we passed from length to surface, and from surface to body' (Aristotle 2012, 268a:25-30). For further reference on Aristotle's mention of the dimensionality in other works, see (Cajori 1926).

2 Mentioned in Cajori (1926: 397), original description appearing in (Heiberg 1893: 7a, 33).

3 Joseph-Louis Lagrange (1736-1813), a French-Italian mathematician, and his colleague Jean-Baptiste le Rond d'Alembert (1717-1783) mathematician, philosopher, co-editor of Encyclopédie, the first modern encyclopedia (by known contributors), published between 1751 and 1772 .
} 


\section{It's Elementary}

In the first half of the nineteenth century, some German geometers began to write about it. An interesting musing by August Ferdinand Möbius $(1827)^{4}$ gave an illustration that is worth mentioning: if one had a crystal, structured like a lefthanded staircase, what would be the transformation to get the right-handed staircase crystal? Möbius concluded that it could be done by passing the object through a fourth dimension to gain its three-dimensional reflection. At this point, it is worth considering how dimensionalities arise from 0 to 4 .

If we start from the zero dimension we have a point: a point is that which has no part (Euclid, Elements, I:1).

The first dimension is generated by a single movement of this point: it creates a line, containing an infinite number of points; the only possible figure in this dimension is a line segment limited by two points as its boundaries.

The second dimension is thus created by analogy by the movement of the line perpendicular to itself. Whilst an infinite number of polygons can be drawn in this dimension, let us for the moment stick to the square as generated by the movement of our original line segment, moved at a perpendicular point to itself, to a distance equal to its length.

The third dimension, or 3-fold can be generated by the movement of our square in the direction perpendicular to its own plane. The figure that we are generating will give us a cube: the square that we have moved to create the 3 -fold will be at a distance equal to the length of the square which we used in generating the cube.

In fact we can by the same process generate any number of dimensions, and this is how William Stringham described it.

A pencil of lines, diverging from a common vertex in $n$-dimensional space, forms the edges of an $n$-fold (short for $n$-dimensional) angle. There must be at least $n$ of them, for otherwise they would lie in a space of less than $n$ dimensions. If there be just $n$ of them, combined two and two they form 2-fold face boundaries; three and three, they form 3-fold trihedral boundaries, and so on. So that the simplest $n$-fold angle is bounded by $n$ edges, $\frac{n(n-1)}{2}$ faces, $\frac{n(n-1)(n-2)}{1 \cdot 2 \cdot 3} 3$-folds, in fact, by $\frac{n !}{k(n-k) !} k$-folds. Let such an angle be called elementary (Stringham 1880: 1).

If we therefore go back to our description of dimensions, and consider the fourth dimension, we would move the cube perpendicularly to itself in this fourth dimension, to a distance equal to the three dimensions of the original cube. We would then generate the four-dimensional hypercube, or tesseract (Fig. 1).

Stringham tried to illustrate the creation of the four-dimensional analogues of the known three-dimensional geometrical objects both mathematically and diagrammatically: the few illustrations are given in Fig. 2.

\footnotetext{
$\overline{4}$ As reported by (Robbin 2006), 3.
} 

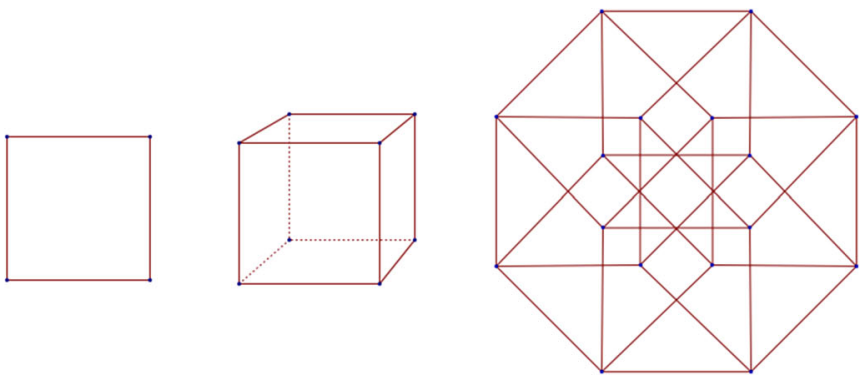

Fig. 1 Starting from the zero dimension, which is represented by a point, we generate a one-dimensional object, the line segment. Further by moving the line segment perpendicularly to itself we generate a square, a two-dimensional object. By moving the square perpendicularly to itself we generate a cube. The cube, a three-dimensional object, moves perpendicularly to itself to generate the four-dimensional hypercube, or tesseract. Image: author

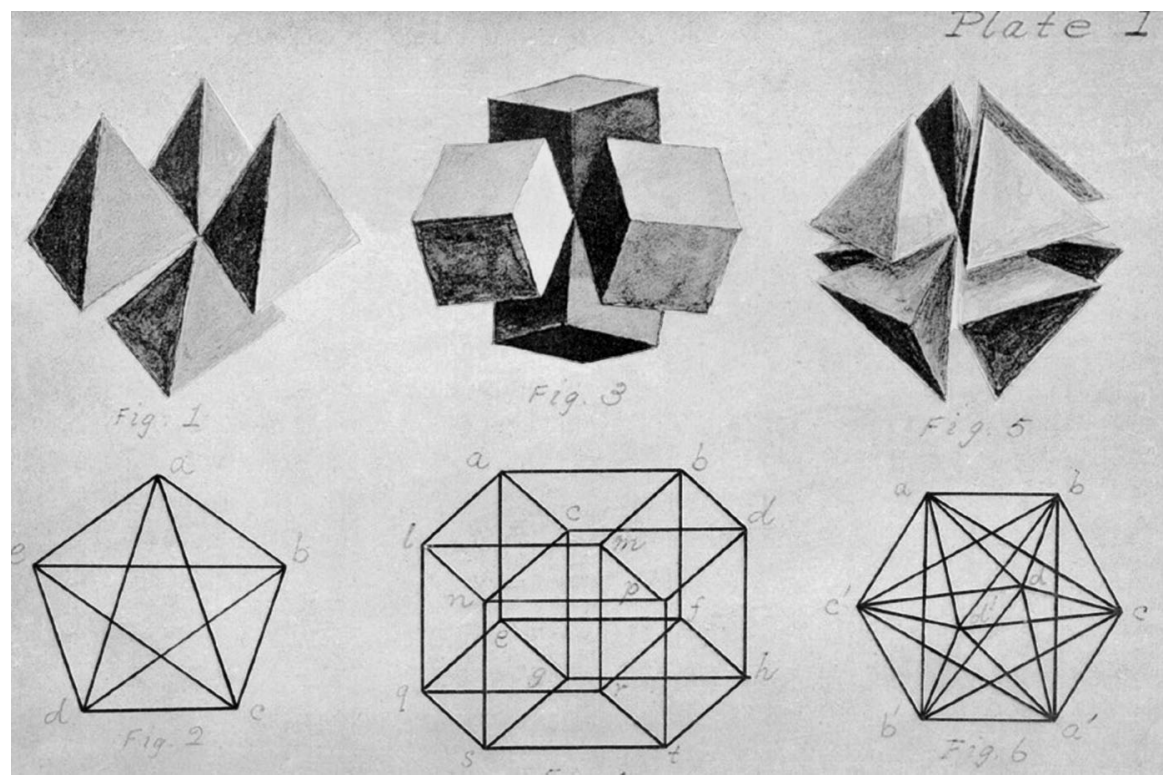

Fig. 2 These represent 'respectively summits, one in each figures, of the 4-fold pentahedroid, oktahedroid, and hexadekahedroid, with the 3-fold boundaries of the summit spread out symmetrically in three dimensional space' (Stringham 1880: 6)

We now need to go a bit back in time to see more about both the development of the concept of the fourth dimension and to understand and possibly visualize it better ourselves.

\section{Untangling the Yarn a Bit Further}

Stringham's (1880) paper was not the first to discuss the steps of imagining, or generating the dimensions starting from zero. Ludwig Schläfli (1814-1895), in his 
book Theorie der vielfachen Kontinuität, (Theory of Continuous Manifolds), published in 1852, wrote about the four dimensions and had some beautiful findings about the regular polyhedra that transcended dimensions. Schläfli started by studying platonic solids and Euler's theory of polyedra.

Platonic solids are regular convex polyhedra, subset of three-dimensional space bounded by congruent faces of regular polygons, with the same number of faces and the same numbers of edges meeting at each vertex. Only five polyhedra satisfy this criteria (i.e., the same number of regular polygons meeting at each vertex): tetrahedron, cube or hexahedron, octahedron, dodecahedron, and icosahedron. ${ }^{5}$

Schläfli looked at the work that Euler did little less than a century earlier, in a paper Elementa doctrinae solidorum (Euler 1758), where he described one of the important characteristics of solids (applicable to platonic solids, but valid for all convex polyhedra in three dimensions). This characteristic is now called Euler's characteristic (sometimes, mistakenly, also called Euler's formula ${ }^{6}$ ); it is a topological invariant, a number that describes a topological space's structure. Euler described it in his paper in the main theorem, which says that in all convex solid bodies the sum of the solid angles and the number of faces is equal to the number of edges plus two (Fig. 3).

We now denote this characteristic by $\chi$ (Greek letter chi) and describe it as $\chi=V-E+F$; and for convex polyhedra $\chi=V-E+F=2$, where $V$ is the number of vertices, $E$ is the number of edges, and $F$ is the number of faces in a polyhedron. If we further analyse the formula we notice that we begin from the first variable which counts points (point we earlier took to represent zero dimension); the second variable which numbers the edges in a solid (representing line, first dimension) and the third variable, numbering the faces of a solid (polygon is bound part of a plane, representing the second dimension).

Schläfli (1852) showed that this formula is also valid in four dimensions and indeed any higher dimension. He first defined a system which would describe any regular polytope ${ }^{7}$ in any dimension. There is only one polytope in the first dimension, a line segment, and the Schläfli symbol denoting this is \{\}. Regular polygons in two dimensions are, for example, triangle $\{3\}$, square $\{4\}$, pentagon $\{5\}$, etc. Remembering that he only used these symbols to denote regular polytopes, we continue. In three dimensions the five regular polyhedra, platonic solids, ${ }^{8}$ can be described by Schläfli symbols as shown in Table 1 .

\footnotetext{
5 Semiregular polyhedra have different types of regular polygons as faces but are organized in the same way around each vertex. They can be divided into prisms (two congruent $n$-sided polygons and $n$ parallelograms), antiprisms, and the Archimedean solids. For the history of the five regular polyhedra see (Lloyd 2012).

${ }^{6}$ Euler's Formula is rather $e^{i x}=\cos x+i \sin x$, the special case of which is $e^{i \pi}+1=0$.

7 Polytope as a general name for a figure of any dimension appears for the first time in English Language in 1908 (OED, accessed online 1st November 2013, http://www.oed.com/view/Entry/ 236624? redirectedFrom=polytope\#eid).

8 There is now a way of describing semi-regular polyhedra with Schläfli symbols, but that is our adaptation of the system which was not originally designed for non-regular polytopes.
} 


\section{DEMONSTRATIO.}

\section{Scilicet fi ponatur ve hactenus: numerus angulorum folidorum $=\mathrm{S}$ numerus acierum $-\cdot--=\mathbf{A}$ numerus hedrarum $--\cdot=\mathrm{H}$ demonftrandum eft, $\mathrm{creS} S+\mathrm{H}=\mathrm{A}+2$.}

Fig. 3 Euler's characteristics first described (Euler 1758: 119)

Table 1 Descriptions of the five regular solids in Schäfli notation

$\begin{aligned} & \{3,3\}, \\ & \text { Three-sided polygons meet three at each vertex to form } \\ & \text { tetrahedron }\end{aligned}$
$\begin{aligned} & \{4,3\}, \\ & \text { Four-sided polygons meet three at a vertex to form cube }\end{aligned}$ $\begin{aligned} & \begin{array}{l}\text { Three-sided polygons meet four at a vertex to form } \\ \text { octahedron }\end{array} \\ & \begin{array}{l}\text { Three-sided polygons meet five at each vertex to form } \\ \text { icosahedron }\end{array}\end{aligned}$

Schläfli then showed that Euler's characteristic can be represented in a slightly modified form: he stated that $V-E+F-C=1$, in effect stating that the number of vertices, minus the number of edges, plus the number of faces, minus the number of cells, equals one. Cell in three dimensions is a solid (convex); so for a cube this formula would be: 


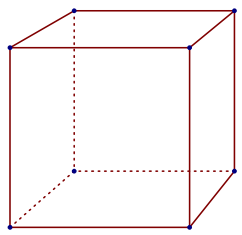

$$
8 \text { (vertices) }-12 \text { (edges) }+6 \text { (faces) }-1 \text { (cell) }=1
$$

and for the hypercube, or tesseract, it would be

16 (vertices) -32 (edges) +24 (faces) -8 (cube cells) +1 (hypercube $)=1$ (Fig. 4).

In fact Schläfli showed that the minus plus pattern continues with even dimensions (dimensions $0,2,4$ and so on) having positive values and odd (1, 3, 5, etc.) having negative values. This was a big breakthrough: by extending the validity of Euler's characteristic to the fourth and any other higher dimension, Schläfli showed that it was possible to calculate various characteristics of four-dimensional polytopes when certain other information is available. This also meant that the fourdimensional solids could be now identified, classified, and studied.

Studying the fourth dimension became something of a vogue in the nineteenth century; some believe that the most influential paper on it was that of Riemann ${ }^{9}$ his Habilitation lecture given on 10 June 1854, introduced the $n$-dimensional manifold into mainstream mathematics. Among other (significant) mathematicians who wrote on it, in addition to those already mentioned were Hermann Günther Grassmann (1844), William K. Clifford (1873), and Arthur Cayley (1885). ${ }^{10}$ But there was a particular side to this which leads us further to the contemplation of two other issues this present paper set out to investigate: firstly that on the meaning of higher dimensions and how accepting the possibility of their existence reconcile with our own life experiences. Secondly, this inevitably, in a few cases, resulted in contemplation on how architecture of three dimensions may respond to the world that is multidimensional. Let us now look at the first of the two issues.

\section{The Radio-Waves and the Dead People}

Whilst perhaps we would not expect a world renowned applied mathematician or physicist today to become a member of a sect, I would ask the reader to consider the possibility that what turned out to be a laughable matter was not so at the outset. The protagonists of this part of the story are Johann Karl Friedrich Zöllner (1834-1882), the inventor of the astrophotometer, ${ }^{11}$ and his English friend Sir William Crookes (1832-1919), Fellow of the Royal Society. ${ }^{12}$

\footnotetext{
9 Bernhard Reimann (1826-1866), a German mathematician. See (Riemann 1873) for further reading

${ }^{10}$ For further information see (Polo-Blanco 2008; Coolidge 1940; Robbin 2006).

11 The astrophotometer, invented in 1856 , is able to compare the real with artificial stars based on the brightness and colour emanating from both.

12 Crookes invented in 1873 his famous Crookes radiometer, which is still sold as a scientific curiosity. Crookes was an accomplished chemist and is credited with the discovery of thallium in 1861 and the identification of the first known sample of helium in 1895.
} 

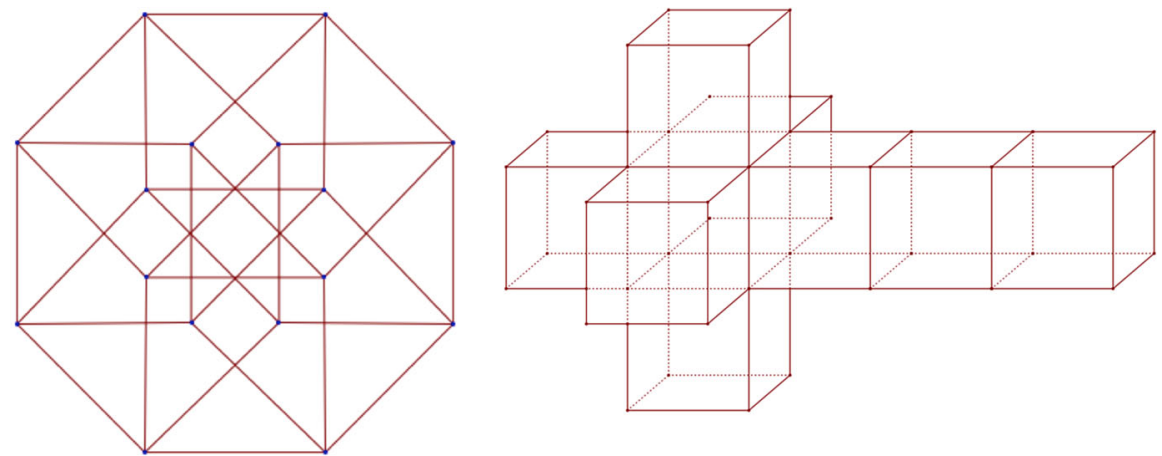

Fig. 4 Tesseract graph (left) and tesseract net (right)

Zöllner became interested in the study of non-Euclidean and four-dimensional geometries and came to the conclusion that these two geometries (perhaps at the same time) could help us explain many physical phenomena. He, similarly to Möbius some half a century earlier, thought about an object getting 'out' of a dimension to perform a spatial 'operation'. His example was about a circle and the point outside of it (Fig. 5). How can this point get into the circle without cutting the circumference? If the point left the plane in which they both were, it could, thought Zöllner (1878). ${ }^{13}$

But Zöllner went a bit further and applied his theory to his work in physics and especially in astrophysics. In fact he became the first professor of Astrophysics at the University of Leipzig. His work Über Wirkungen in die Ferne (On effects at a distance) (Zöllner 1878), ${ }^{14}$ part of his Wissenschaftliche Abhandlungen (Scientific Treatises), was borne out of his contemplation on the matter of four dimensions, but also out of his friendship and scientific as well as occult cooperation with Crookes. Both Crookes and Zöllner were interested in transmission of energy and the theory of waves, and Crookes experimented on conduction of electricity in low-pressure gasses. They became friends in 1875 when Zöllner visited Britain. They were also, it seems, convinced that the fourth dimension was inhabited by beings who we cannot grasp in their entirety as we are confined to the three dimensions, but that we could perhaps get in touch with them and communicate via mediums; in other words, both were keen spiritualists. ${ }^{15}$

\footnotetext{
13 Also described by Steiner in his first lecture on the fourth dimension, Berlin, 24 March 1905 (Steiner 2001).

14 An interesting coincidence is the famous poem by a Goethe (1749-1832) with the same name; its lighthearted referral to spirits is a recommended further reading. Available online at: http://en.wikisource. org/wiki/The_Works_of_J._W._von_Goethe/Volume_9/Effect_at_a_Distance.

15 Crookes perhaps went much further than Zöllner although we have no record of the latter's occult activities. Crookes was a president of the Society for Psychical Research in 1890s, joined Theosophical Society and the Ghost Club the latter of which he was president 1907-1912. He then became an initiate in the Masonic-Protestant sect called the Hermetic Order of the Golden Dawn in 1880. Whilst to us it may seem strange that these interests coexisted in Crookes and Zöllner, they were not alone in this period. Some other of his fellow scientists who joined some or all of the occult organizations that Crookes joined were Alfred Russell Wallace (1823-1913), geographer, anthropologist and biologist, who published jointly with Charles Darwin), Oliver Lodge (1851-1940, physicist, one of the inventors of wireless telegraphy), and John William Strutt (3rd Baron Rayleigh, (1842-1919), physicist, co-discoverer of argon, winner of Nobel Prize in 1904 for his work on surface waves and the theory of sound.
} 
Fig. 5 Zöllner illustratates that in order to perform certain operations in space, objects must exit their dimensions

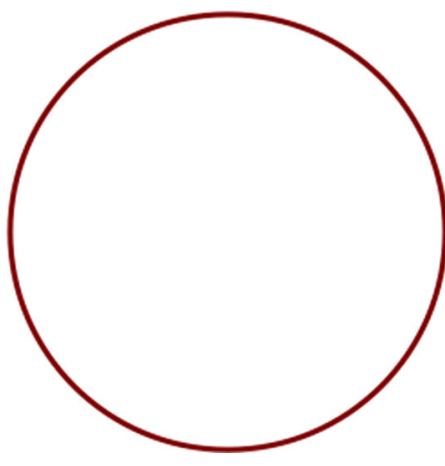

Descriptions of spiritualism are abundant: the belief was that some people (mediums) are able to get out of our dimension in spirit and enter the parallel universe whilst their bodies were still in the three-dimensional world. This other higher world was apparently inhabited by other beings and mediums would communicate with these beings while remaining with their physical bodies in the room with other spiritualists. So unorthodox was this belief that even spiritualists wrote many apologetic descriptions and justifications for their work. ${ }^{16}$ However, this had some relation to the then current investigations on the fourth dimension as the following quote testifies:

Why then might not spirits be beings of the fourth dimension? Well, I will tell you why. Although we cannot hope ever to comprehend what a spirit is-just as we can never comprehend what God is-yet St. Paul teaches us that the deep things of the spirit are in some degree made known to us by our own spirits... Even if we could conceive of space of four dimensions-which we cannot do, although we can perhaps describe what some of its phenomena would be if it existed-we should not be a whit the better morally or spiritually (Abbott 1897: 29).

This above quote was written by no one else but our next protagonist, Edwin Abbott Abbott (1838-1926), a London schoolmaster, Shakespearean scholar, and author of the probably most popular mathematical novella of all times, the famous Flatland.

\section{Flatland and Our Ability to Transcend the Dimensions to Which we are Confined}

Flatland is a land that is flat. It is

like a vast sheet of paper on which straight lines, triangles, squares, pentagons, hexagons, and other figures, instead of remaining fixed in their places, move freely about, on or in the surface, but without the power of rising above or

\footnotetext{
$\overline{16}$ See for example (Abbott 1897), and (Boole 1911).
} 
Fig. 6 The most common construction for a house in Flatland, with separate doors for men and women. Image: (Abbott 1884: front page and p. 5)

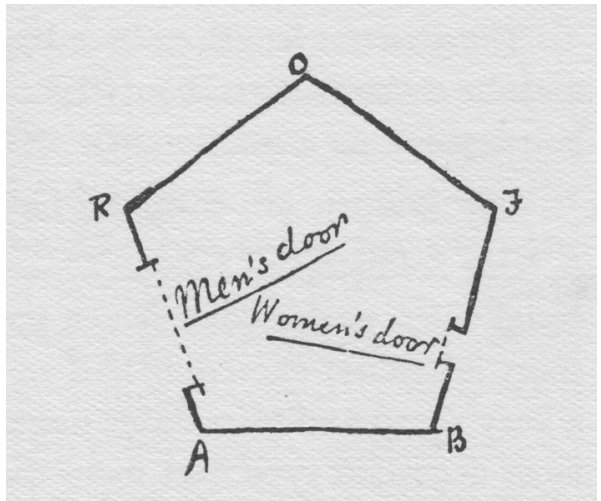

sinking below it, very much like shadows-only hard and with luminous edges - and you will then have a pretty correct notion of my country and countrymen... (Abbott 1884: 29).

The significance of the Flatland and the image of Flatlanders as beings stuck in their two-dimensional universe where every three-dimensional being is considered either mystical or an intruder, drew upon the imagery from the spiritualist movement. This had a lasting impact on the popular psyche it seems. If you have ever read flatland or any of its sequels, ${ }^{17}$ you will soon learn why: you cannot escape being captured by the contemplation of the dimensionality of our world and our perception of it. Abbott certainly succeeded when he set out to make his audience think about the possibility of the fourth dimension and the morality and politics of our own, three-dimensional world.

From the very beginning of the story about Flatland, the questions of ethics and the place of women in the world (and in mathematics) begin to form. The twodimensional beings are stuck in a reality where three-dimensional beings appear mystical, but they are also stuck in the belief that women should be treated in a different way from men. One of Abbott's illustrations from this strange world of Flatland shows that very clearly. The house model shows that 'the East is a small door for the Women; on the West a much larger one for the Men' (Fig. 6).

Furthermore, the women are all straight lines, while the men, depending on their social position in society, can be triangles (workmen and soldiers), equilateral triangles (middle classes), squares and pentagons (professional men and gentlemen) or even hexagons (nobility). Of course Abbott was trying to make a philosophical and social, rather than geometric point with his novella.

The Flatlanders cannot understand or visualize the third dimension: in the story this only happened to the main protagonist, the Square. He had an almost mystical experience of meeting a sphere. First he only saw Sphere through Sphere's intersections with Flatland (Fig. 8), but eventually Sphere spoke to Square. The 'mystical' wasn't that at all, as Sphere explains:

\footnotetext{
17 Sequels of Flatland include (Hinton 1907) and (Stewart 2001).
} 


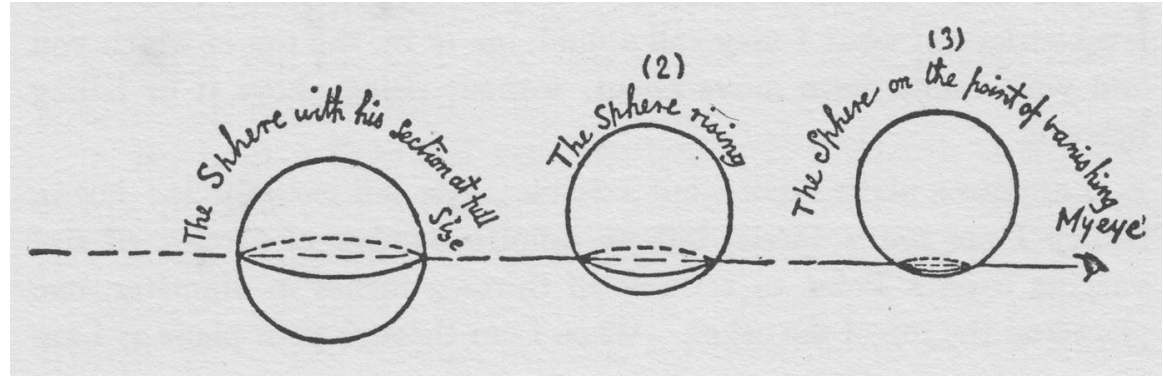

Fig. 7 The diminishing sphere leaving projections in Flatland, its cross sections (circles). Image: (Abbott 1884: 72)

Surely you must now see that my explanation, and no other, suits the phenomena. What you call solid things are really superficial; what you call space is really nothing but a great plane. I am in space, and look down upon the insides of the things of which you only see the outsides. You could leave this plane yourself, if you could but summon up the necessary volition. A slight upward or downward motion would enable you to see all that I can see (Abbott 1884: 2).

Of course Sphere is stuck in his own world of three dimensions: when, towards the end of the story Square regurgitates the analogy between dimensions and speaks of projections of four-dimensional bodies in three dimensions, the Sphere exclaims a simple "nonsense!" (Abbott 1884): of course there is no higher dimension than that which he can experience (Fig. 7).

Whilst Flatland was a work of fiction, it had a serious impact on the further study of the fourth dimension in Victorian England. The realisation that three-dimensional solids can be described as projections of four-dimensional ones, was another breakthrough in the study of the fourth dimension. Now the quest to describe and classify the four-dimensional polytopes, as well as illustrate them via their threedimensional projections, became urgent.

Abbott's contemporaries were George Boole (1815-1864) the celebrated mathematician, and the inventor of Boolean logic, and his wife, self-taught mathematician and mathematics educator Mary Everest Boole (1832-1916). ${ }^{18}$ George died of pulmonary disease at the age of 49 and Mary worked from then on as a librarian at Queen's College, London. ${ }^{19}$ It is likely Mary and Abbott either knew of each other or knew each other personally. At the time Abbott lived in Marylebone and worked as a school master at City of London School. It is certain, from her own records, that Mary knew and was working as secretary to James Hinton soon after 1865. Hinton (1822-1875) was a naval doctor and an author, and was described by

\footnotetext{
18 Mary's uncle was George Everest (1790-1886), Welsh surveyor and geographer, explorer of Mount Everest.

19 Mary's most popular and well known publication for children is Philosophy and Fun of Algebra (1911), in which she mentions some of the principles of Boolean algebra.
} 
his contemporaries as compassionate and idealistic. ${ }^{20}$ But James was also a spiritualist, and it seems that Mary became one too. Whilst Mary wrote interesting books for children on mathematics, at the same time she defended spiritualism:

... the most important part of any new truth is not always that which at first excites the most discussion; that a force which was spiritual when we were ignorant of the laws of its operation does not become unspiritual because we have discovered a few of those laws; and that knowledge which was divine when it was vague and partial is not necessarily made "satanic" by an effort being made to render it more complete and accurate... The leaders (of the Society for Psychical Research), many of whom are men of unquestioned ability, will pursue their course in a spirit of calm and patient enquiry, equally unmoved by the satire and antagonism, and by the over-excited curiosity and too ready belief, which will seethe around them (Boole 1908: xiv).

Hinton had a son, now famous for his take on the fourth dimension. The young Hinton, Charles Howard Hinton (1853-1907), authored a few works on the fourth dimension $^{21}$ and married Mary's oldest daughter, also named Mary. Whilst this can turn into discussion about life itself (Charles bigamously married a second time within 3 years of his first marriage), the primary interest of Charles in our story is his teaching of Alicia, Mary's youngest daughter, about the fourth dimension. Charles Hinton taught Alicia to visualize the fourth dimension and to contemplate the intersections of the four-dimensional bodies with the three dimensional space.

Alicia Boole Stott (1860-1940), an amateur mathematician, met Pieter Hendrik Schoute (1846-1913), a professional mathematician from the University of Gröningen in 1894, and they began the life-long collaboration and friendship. Pieter illustrated, in the same year, some four-dimensional polytopes by making models using silk thread and brass wire. Alicia learnt of this via her husband, who was an engineer, and the two were introduced.

Alicia had an intense period between 1894 and 1913 working on the visualizing of four-dimensional polytopes, describing them, and making models of their three dimensional projections. She left a considerable collection at the University of Gröningen where she was awarded an honorary doctorate in 1914, after the death of her friend and collaborator Schoute. Later in life Alicia met Donald Coxeter (1907-2003), and had a profound influence on his work. ${ }^{22}$

Whilst Boole Stott contributed to establishing the study of the fourth (and higher) dimensions on scientific principles, her academic achievement was incidental and her collaborations were limited to men she met outside of the official academic channels. Without doubt though, the traces of what the four-dimensional bodies really look like rest on her capacity to visualize them. Through her work she also

\footnotetext{
${ }^{20}$ He was a friend of Sir William Withey Gull who was involved with the Jack the Ripper murders.

21 Charles Hinton's most famous works are Scientific Romances: First and Second Series (1884), A New Era of Thought (1888), The fourth dimension (1904).

22 Both gave her all due credit for her contributions both in terms of their joint work and for her inspiration and visualizing capabilities; Coxeter fondly called her Aunt Alice as he was introduced to her by his friend, Alice's nephew, G. I. Taylor (1886-1975) a Cambridge mathematician.
} 
showed what could be achieved by a woman studying mathematics, even in the Victorian society that Flatland parodies.

The Society for Psychic Research which Alicia's mother defended, and Theosophy, later Anthroposophy, ${ }^{23}$ were not too far from each other. Rudolf Steiner (1861-1925), the founder of the latter, was inspired by the work of Hinton and Abbott and himself delivered lectures on the fourth dimension. The Theosophy had a strong connection with women's rights and socialist movements through the leadership of Annie Besant (1847-1933). This aspect of the movement, and consequently Steiner's own interpretation and work on establishing Anthroposophy are best described thus:

This higher world (of the four-dimensional ${ }^{24}$ ) was feminine, nurturing, free of social and legal restraint.

Out of these sentiments Steiner imagined his Goethaneum and the architecture which was in some ways should enable us to develop our perception of the world. ${ }^{25}$ This for Steiner, should include a certain training in spiritual science, part of which was his belief that people can develop and learn to view the fourth dimension. This was not a unique position: whilst this paper does not give us enough space to discuss the full extent to which the fourth dimension was considered within Theosophy and Anthroposophy, it is important to note the view of the connection between the study of the fourth dimension and geometry as a science which could offer an insight into the secrets at the core of life on Earth. In particular, the understanding that fourdimensional beings intersect with three-dimensional reality became a widely accepted view in Theosophy and Anthroposophy (Fig. 8).

Steiner's first and second Goetheanum buildings are thus the first architectural objects that embody the principles of contemplation of the fourth dimension. These two buildings were (the first was burnt to the ground in 1922) and are (the second still in existence) the headquarters of Steiner's Anthroposophy movement in Dornach, Switzerland. They were built to provide a place where the training in visualizing higher dimensions (amongst other things) could be undertaken. His understanding of the fourth dimension is recorded through the lectures he gave in Berlin in March of 1905 and which he taught on his lecture tours. In the second recorded lecture of the 1905 series, he describes the fourth dimension and the reasons why everyone should be trained in visualizing it:

The unique structure of our sensory apparatus enables us to make our mental images coincide with outer objects. By relating our mental images to outer things, we pass through four-dimensional space, putting the mental image over the outer object... The astral world itself is not a world of four dimensions. Taken together with its reflection in the physical world, however, it is four-

\footnotetext{
23 Theosophical Society began in 1875 to advance the study of theosophy and Anthroposophical Society was a splinter group of the same, founded by Rudolf Steiner in 1907.

24 David Booth, in Steiner 2001: xv.

25 Steiner was primarily a philosopher and a Goethe scholar; he later became founder of Waldorf Education, and later in life an architect. Between 1908 and 1925 when he died, Steiner designed and supervised the building of seventeen buildings.
} 


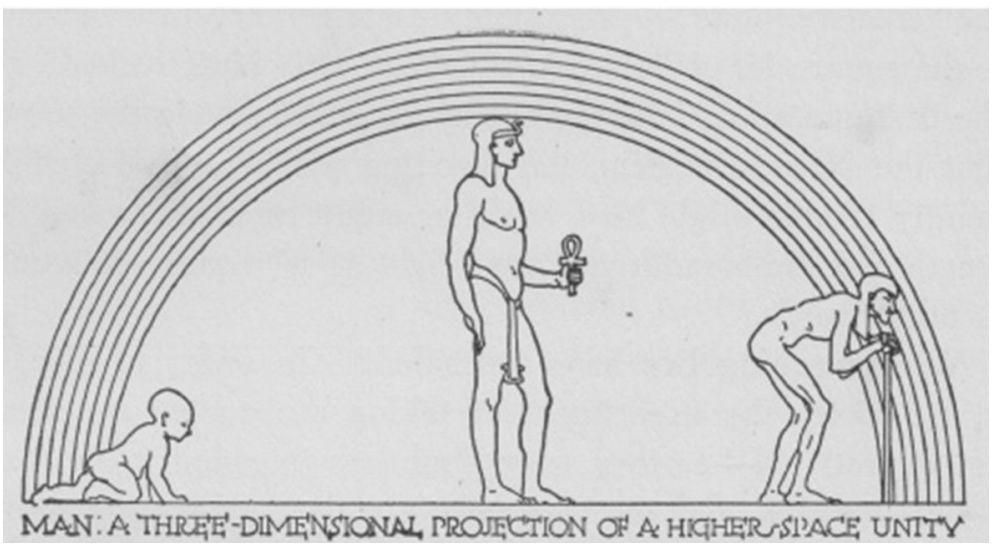

Fig. 8 An image of the ages of man as third projections of four-dimensionality in our three dimensional world (Bragdon 1913: 63)

dimensional. When we are able to survey the astral and physical worlds simultaneously, we exist in four-dimensional space. The relationship of our physical world to the astral world is four-dimensional. ${ }^{26}$

Perhaps this is a good time to turn to less occult views of the fourth dimension and see more popular manifestations of architecture that may mirror an understanding of this geometrical concept, lest we should get lost in the astral world.

And He Built Me a Crooked house

Time is a fourth dimension, but I'm thinking about a fourth spatial dimension, like length, breadth, and thickness. For economy of materials and convenience of arrangement you couldn't beat it. To say nothing of the saving of ground space-you could put an eight-room house on the land now occupied by a one-room house. Like a tesseract...

Robert A. Heinlein, And He Built a Crooked House, 1941

More than three decades after Steiner's lectures, in 1941, at the outset of the World War II, before America's involvement in it, a pulp-fiction magazine published a story about an architect who builds a house of four dimensions. He does this because he is bored with the old-fashioned architectural designs, "Even the Moderns-all they've done is to abandon the Wedding Cake School in favor of the Service Station School..." (Heinlein 1941), and he wants to save on space. First he thinks that he can in fact build a tesseract, and as the eight cubes fold into the fourdimensional cube the space is saved. But his friend advises him against it while he examines the model the architect made:

${ }^{26}$ Steiner 2001:15. 
Bailey studied the wobbly framework further. "Look here," he said at last, "why don't you forget about folding this thing up through a fourth dimension-you can't anyway-and build a house like this?"

"What do you mean, I can't? It's a simple mathematical problem-"

"Take is easy, son. It may be simple in mathematics, but you could never get your plans approved for construction. There isn't any fourth dimension; forget it. But this kind of a house-it might have some advantages."

Checked, Teal studied the model. "Hm-m-m-Maybe you got something. We could have the same number of rooms, and we'd save the same amount of ground space. Yes, and we would set that middle cross-shaped floor northeast, southwest, and so forth, so that every room would get sunlight all day long. That central axis lends itself nicely to central heating. We'll put the dining room on the northeast and the kitchen on the southeast, with big view windows in every room. Okay, Homer, I'll do it! Where do you want it built?" (Heinlein 1941).

The story ends by the tesseract net folding of its own volition into the fourdimensional cube, leaving inhabitants first stranded inside the four-dimensional structure, and later vanishing. Apart from giving you an obvious reason why you shouldn't ask an architect to design you a house which uses the fourth dimension to save on space, this story also suggests that geometrical concepts that are not confined to the three dimensions and our world of experience, should probably best be left alone. Even though we now know how to study and classify objects in four dimensions, these are not perhaps the best of models or inspiration for a new architecture, so this story tells.

There are some examples to the contrary in the real world: one such is a wellknown and built model of a hypercube, La Grande Arche de la Défense or La Grande Arche de la Fraternité. The building was completed in 1989, to celebrate the 200 years of the French Revolution, and was built by the Danish architect Johann Otto von Spreckelsen (1929-1987) and engineer Erik Reitzel (1941-2012). This particular building is a simple representation of the tesseract-its imposing structure and the dramatic views celebrate both the French Revolution and the revolutions that happened around the science of geometry since the French Revolution took place. The latter revolutions could certainly adopt the following as its manifesto:

We have Einstein's space, de Sitter's space, expanding universes, contracting universes, vibrating universes, mysterious universes. In fact, the pure mathematician may create universes just by writing down an equation, and indeed if he is an individualist he can have a universe of his own (Greenberg 1980: 132).

Another example, not quite real (not yet built) would be the highly publicized Dynamic Architecture skyscrapers by the Italian-Israeli architect David Fisher (b 1949). These buildings are imagined as consisting of differently shaped floors which permanently rotate on the middle axis, providing users with the constantly changing view of the cityscape below. 


\section{Our Four-Dimensional Lives}

We float in the sea of the fourth dimension like ice in water

Rudolf Steiner

Second lecture on the fourth dimension

Berlin March 31, 1905

Some conclusions then, that the history of the study of the fourth dimension can offer to us back here in the third dimension (or is it the eleventh?) perhaps are as follows.

Firstly, most of the protagonists of our story who contributed to the study of the fourth dimension were interested in Kantian philosophy, whether they explicitly stated it like Steiner, or not, like Abbot. ${ }^{27}$ They discussed at length the difference between noumenal and phenomenal worlds and the nature of knowledge, and used geometry as a model of the world. This quest for knowledge included an examination of the layers or dimensions of our worldly experience. The study of geometry became intertwined with the social and moral issues of their times, and they used geometrical imagery to illustrate their world.

Second conclusion has a moral to it, as it were, and could be taken as a lesson: even when we feel stuck in a dimension which we really don't understand (literally or metaphorically), we can invent a new apparatus which relies on some old truths. This is what Schläfli did, for example. He was then able to continue pushing the boundaries of understanding of the fourth and higher dimensions as a concept, although he did not come up with complete answers. Nevertheless, he made it possible for such theories to be further explored, and such higher-dimensional objects to be visualized, as they were by Boole-Stott.

Another example related to working within a new area of knowledge is related to interpretation: whilst same of our protagonists thought that there was some mystical aspect behind the study of the fourth dimension, this still didn't stop them making real and positive contributions to applied and very 'worldly' mathematics. Examples of this could be seen in the cases of Zöllner's and Crookes's lives and works.

In terms of architecture, there seem to be two interpretations of the fourth dimension. The first is related to the Anthroposophy's influence ${ }^{28}$ and linkages between the study of the fourth dimension as a necessary part of the "spiritual science" 29 that Steiner established. If we further investigate for example Steiner's principles of design, we find that the ethical considerations are directly linked to the study of the fourth dimension. This particular interpretation can lead to the following questions: Can it be that we are stuck in the third dimension because we are not doing things right? (the 'Ground Hog Day' film analogy to a philosophical

\footnotetext{
27 See in particular (Steiner 2001) and (Abbott 1897).

28 Architects influenced by Anthroposophy or being members of the movement, are Hans Scharoun and Joachim Eble in Germany, Erik Asmussen in Sweden, Kenji Imai in Japan, Anto Alberts and Meyer and Van Schooten in Holland, Thompson and Rose in America, Camphill in the UK, among others.

29 All known Steiner's writings translated into English can be seen at http://www.rudolfsteinerweb.com/ Rudolf_Steiner_Works.php (accessed 1st November 2013).
} 
question pops to mind). If we get better at life, will we be allowed to roam free around the multi-dimensional universe? If so, what kind of architecture might we encounter there?

Another type of the interpretation of the fourth dimension in architecture, the unbuilt dynamic skyscrapers, tells us a story of the post-modernist inclinations. We live post-modern lives, ones in which the digital friends probably have more insight into our worlds than our real neighbours. Yet, we are not sure how to tackle or interpret the advances in mathematics and geometry and still tend to treat time as the only meaningful way of illustrating the fourth dimension.

Lastly, whilst there were many strange practices associated with the otherwise mathematically sound studies of the fourth dimension, the social dimension of the study was in fact progressive and inclusive. It actively promoted women's place in society, as can be seen at least on the example of the social manifesto that Flatland put forward. Equally, the daughter and mother, Alicia and Mary Boole, seemed to have escaped the chains in Plato's cave of unknowing, and they managed to do so all on their own merit with the sole help of the science of geometry.

\section{Bibliography}

Abbott, E. A. 1884. Flatland. Seeley \& Co., London.

Abbott, E. A. 1897. The Spirit on the Waters. Macmillan \& Co., London.

Aristotle. c. 350. De Caelo (On the Heavens). Translated by J. L. Stocks, The Clarendon Press, Oxford, 1922.

Boole, M. E. 1908. The Message of Psychic Science to the World. London: C. Daniel; electronic copy at https://archive.org/details/messagepsychics00boolgoog.

Boole, M. E. 1911. The Forging of Passion into Power. M Kennerly, London.

Bragdon, C. F. 1913. A Primer of Higher Space. Manas Press.

Cajori, F. 1926. Origins of Fourth Dimension Concepts. The American Mathematical Monthly, 33:8, 397-406.

Cayley, A. 1885. On the quaternion equation qQ - Qq =0. Messenger of Mathematics 14:108-112.

Clifford, W. 1873. Preliminary sketch of biquaternions. Proceedings of the London Mathematical Society, 4: 381-395.

Coolidge, J.L. 1940. A History of Geometrical Methods. Clarendon Press, Oxford.

David Booth, 2001, xv. Introduction into the Fourth Dimension. Rudolph Steiner, Anthroposophic Press, Massachusetts US, 2001.

Euler, L. 1758. E230, Elementa doctrinae solidorum, Elements of the doctrine of solids. First published in Novi Commentarii academiae scientarium Petropolitanae 4:109-140. St Petersburg.

Everest-Boole, M. 1817. Message of Psychic Science to the World, C. W. Daniel, London.

Grassmann, H.G. 1844. Die Lineale Ausdehnungslehre, ein neuer Zweig der Mathematik. Wiegand, Leipzig.

Greenberg, M. J. 1980. Euclidean and Non-Euclidean Geometries, Development and History. W. H. Freeman \& Co. San Francisco.

Heiberg, J. L. 1893. Simplicii in Aristotelis De caelo commentaria. [Commentaria in Aristotelem Graeca 7. Berlin: G. Reimer.

Hinton, C. 1907. An Episode on Flatland: Or How a Plain Folk Discovered the Third dimension. London: Swann Sonnenschein \& Co.

Heinlein, R. A. 1941. And He Built a Crooked House. Astounding Science Fiction, Street \& Smith Publications Inc. New York. Available at: http://www.math.union.edu/ dpvc/courses/2010-11/ mth053-fa10/assignments/crooked-house.pdf (accessed 23 September 2014).

Lagrange, J. 1797. Théorie des fonctions analytiques. Journal de L'École Polytechnique, Paris. 
Lloyd, D. R. 2012. How old are the Platonic Solids? BSHM Bulletin: Journal of the British Society for the History of Mathematics. Taylor and Francis, London.

Möbius, August Ferdinand. 1827. Der barycentrische Calcul, Verlag von Johann Ambrosius Berth, Leipzig.

Polo-Blanco, Irene. 2008. Alicia Boole Stott, a geometer in higher dimension. Historia Mathematica, 25:123-139. Elsevier.

Riemann, B. (translated by William Kingdon Clifford). 1873. On the Hypotheses which lie at the Bases of Geometry. Nature, 14-17, 36-37.

Robbin, T. Shadows of Reality. New Haven: Yale University Press, 2006.

Schläfli, L. 1852. Theorie der vielfachen Kontinuität. Zürich, Basel: Georg \& Co.

Steiner, R. 2001. The Fourth Dimension (1905). D. Booth, trans. Great Barrington, MA: Anthrosophic Press.

Stewart, I. 2001. Flatterland: Like Flatland, Only More So. Cambridge, MA: Basic Books.

Stringham, W. 1880. Regular Figures in n-Dimensional Space. American Journal of Mathematics, 3, 1: 1-14. John Hopkins University Press.

Wallis, J. 1685. A Treatise of Algebra. Richard Davies, London.

Zöllner, 1878) Über Wirkungen in die Ferne, Wissenschaftliche Abhandlungen. Leipzig.

Snezana Lawrence Dr Snezana Lawrence is a Senior Lecturer in mathematics education at Bath Spa University in Bath, England. She is interested in the history of mathematics and mathematics education. Snezana has published on the history of geometry and its applications in architecture, as well as the image geometry has in popular culture and literature. She believes that an induction into the cultural aspects of mathematics should be a crucial aspect of mathematics education to nurture both enquiring spirit and appreciation of mathematics. Snezana leads Prince's Teaching Institute Mathematics programmes and has contributed to the recent revision of the National Curriculum in Mathematics for the UK. Snezana is on the Advisory Board of the History and Pedagogy of Mathematics group (satellite group of the International Mathematics Union), and writes a regular column on the History of Mathematics for Mathematics Today, called historical notes. She is a keen swimmer. 